\title{
Discount Rates for Economic Appraisal of Public Sector Expenditures
}

\author{
Glenn P. Jenkins \\ Queen’s University, Kingston, Canada \\ and Eastern Mediterranean University, North Cyprus \\ Email: jenkins@econ.queensu.ca
}

\section{Development Discussion Paper: 1980-14}

\begin{abstract}
The question of what is the appropriate discount rate to employ in public sector investment appraisal has been the subject of a theoretical debate in the economics literature for over a decade. In recent years, however, most of the points of disagreement in the theory have become better understood and hence a large degree of reconciliation has taken place. Central to this controversy was whether the appropriate parameter to use as the social discount rate should be the social value of the marginal product of investment in the private sector, the social rate of time preference or the social opportunity cost of capital. This paper presents the different arguments on the Discount Rates for Economic Appraisal of Public Sector Expenditures.
\end{abstract}

Keywords: Discount rates, economic appraisal, expenditure, public sector JEL Classification: $\mathrm{H} 43$

Published as: Glenn P. Jenkins (1980). Discount Rates for Economic Appraisal of Public Sector Expenditures. Canadian Public Policy Vol. 6, No. 3 (summer, 1980), pp. 549-555 
The question of what is the appropriate discount rate to employ in public sector investment appraisal has been the subject of a theoretical debate in the economics literature for over a decade. In recent years, however, most of the points of disagreement in the theory have become better understood and hence a large degree of reconciliation has taken place. Central to this controversy was whether the appropriate parameter to use as the social discount rate should be the social value of the marginal product of investment in the private sector (Hirshleifer, DeHaven and Milliman, 1960), the social rate of time preference (Marglin, 1963), or the social opportunity cost of capital (Harberger, 1969).

The subsequent research of Sandmo and Dreze (1971), Dreze (1974) and Sjaastad and Wisecarver (1977) has delved into the explicit and the implicit assumptions which each of the three alternative discounting methodologies make about the impact of the project and its financing on the economy and the nature of the economy in which it is situated. Their conclusions are that only in very unusual circumstances would the alternative use of public sector funds be entirely private sector investment. Rather, in a wide range of circumstances the relevant methodology for discounting should take into consideration both the displacement of private consumption as well as private investment.

Now that most of the theoretical issues have been largely resolved, the areas of disagreement seem to have shifted to questions concerned with the empirical measurement of the variables used to construct the discounting parameters and with the procedure which is most reliable and informative in the practical application of cost-benefit analysis. In Canada the debate has focused on the decision by the Treasury Board to follow the SOCK approach for discounting public sector projects (Treasury Board, 1976) and on the empirical work of Jenkins $(1973,1977$ a) which has attempted to estimate this parameter. Sumner (1980) has raised a number of reasons why the estimated social opportunity cost rate might be biased upward and concludes that it would be preferable in practical applications of social cost-benefit analysis to use the alternative procedure of shadow pricing forgone investment and discounting with the social rate of time preference. He cites the work of Campbell (1975) as providing a simple set of rules for combining the social rate of time preference with the shadow price of forgone investment for deciding on the acceptability of public sector projects. This conclusion is not well founded, however, because the estimation of the shadow price of forgone investment is highly sensitive to the length of life of the project. Therefore, there exists no simple set of consistent rates of time preference and shadow prices of investment forgone as implied by Campbell (1975:175). From his analysis he concludes that when the costs and benefits are discounted by the social rate of time preference, the present value of social benefits should be $1 \frac{11}{4}$ to $2 \frac{1}{4}$ times the present value of costs for a project to be acceptable in Canada. Not 
only is the range of these 'reasonable' estimates so broad as to be of limited value for operational purposes, but their application to projects of different lengths of lives yields disturbing results.

Consider a project which employs labor for one period to clear a drainage canal which will then function properly for only one period so that at the end of period 2 the project will have to be repeated. In this project the present value of costs is equal to the current wage bill, $W_{1}$, while the present value of benefits is equal to the value of the increased benefits from the cleared ditch $\left(B_{2}\right)$ discounted for one period by the rate of time preference $(r)$. Therefore, according to the rule proposed by Campbell the project is a good one if,

(1) $\left(\mathrm{B}_{2} /(1+\mathrm{r})\right) / \mathrm{W}_{1} \geq \mathrm{k}$,

where $\mathrm{k}$ is Campbell's estimated 'shadow' benefit-cost ratio which in turn is estimated from the shadow price of forgone investment.

If $\mathrm{k}$ has a value of two, this implies that the government could economically justify the employment of a person to clear the drainage ditch only if the present value of benefits (the present value of the marginal product of labor) were twice the wage bill for labor! A rigorous application of Campbell's rule would certainly have a profound impact on the size of the public sector in Canada.

Fortunately (for the civil servants), it is Campbell's simplistic criterion which is deficient. This rule assumes that the impact of government financing of a project has a permanant impact on the mix of consumption and investment in the economy. Therefore, the economic cost per dollar of displaced private investment is the same for a project which has a life of 30 days as for one with a life of 30 years. This assumption is not likely to be valid, but it does have an overwhelming impact on the choice of projects. Hence, if the social rate of time preference were used as a discount rate, it would be necessary to construct a different set of 'shadow' cost-benefit ratios for each project which has a different length of life. It would be difficult to exaggerate the likely confusion amongst analysts, policy makers, and interest groups if such procedures were implemented.

In contrast, discounting with the social opportunity cost of funds implicitly assumes that the impact of the project's financing on the economy lasts only for the duration of the project (Sjaastad and Wisecarver, 1977:521-523). This implies that it is the norm for depreciation to be made available for reinvestment. While this assumption may not always hold, it certainly appears more reasonable than to assume that the impact of government borrowing for a project permanently alters the mix of consumption and investment in the economy.

Sumner $(1980)$ in his review of the empirical estimations by Jenkins $(1973,1977)$ outlines five reasons why he believes these estimates have yielded too high a rate. Some of these same points have been raised by analysts from the Province of Manitoba (National Energy Board, 1979). His objections deal primarily with the estimation of the economic rate of return by sector. In summary, they are: (a) the empirical estimates as they now stand include an element of risk; (b) the estimates are based on average rates of return from alternative uses of funds, not on their marginal returns; (c) monopolistic returns may exist in some industrial sectors, but they should not be included in the estimation of the SOCK because no investment will be forgone from these sectors; (d) the historical rates of income tax are higher than current rates and thus the historical economic return from private investment will be higher than can be expected in the future; (e) the sales tax adjustment to the rate of return on investment is too large because some of the sales taxes might have been levied to offset negative externalities. 
Textbooks and some manuals in cost-benefit analysis (Treasury Board, 1976) have recommended that the net benefits of a project be discounted with a risk free rate of opportunity cost, but only after the net benefits have been adjusted to reflect their certainty equivalent values. Sumner also recommends that no risk premium should be included in the discount rate. While this method is perhaps the most theoretically pure procedure to account for the risk associated with a project, it is seldom, if ever, implemented in practice. By far the most common practice is to impose a risk premium on the discount rate to account for the fact that the distribution of benefits and costs of the project cannot usually be completely diversified among the individuals in the economy.

Arrow and Lind (1970) have suggested that if the variance in the flows of benefits and costs from a public sector project could be diversified completely across a country's population, then no risk premium should be included in the discount rate or reduction made in the value of net benefits as a compensation for risk. For projects which are small and whose costs and benefits are widely spread, the assumption of zero undiversified risk is perhaps justified. Simply because public sector projects are undertaken by governments, however, does not mean that they do not create undiversified risk. The absence of tradeable financial instruments whose return reflects the benefits and costs of public sector projects inhibits the diversification of the risk created by the activity. For example, it would be easy to imagine a situation where the benefits and costs of an incremental private investment in an automobile factory or steel plant would be more diversified through the utilization of the capital market than would be a public sector investment in a highway, a school, an electricity generator or a hospital. Regional development projects impose risk on communities which undertake local infrastructure investments and employees who make personal investments or become committed to a career. One need only consider the plight of the communities surrounding the government-financed Come-by-Chance refinery in Newfoundland when it went into bankruptcy to appreciate why a risk permium may be appropriate in an economic or social cost-benefit analysis of a public sector project.

Jenkins' estimation of the SOCK for Canada contains a compensation for risk equal to the average risk premium demanded by private sector investors in Canada. I see no reason to believe that the average public sector project inflicts less risk on those who pay its costs and receive its benefits than does the average private sector project. It would seem to be a more neutral treatment to assume that the average public sector project is as risky as the average private sector project than to assume that public projects generate zero risk. Given our present level of economic technology for the estimation of the degree to which the risk from public sector projects can be diversified, it is unlikely that in the near future we will be able to derive a precise measure of the costs of risk associated with each and every project.

II WILL THE USE OF AVERAGE RATES OF RETURN FROM PRIVATE INVESTMENT GIVEAN UPWARD BIAS TO THE ESTIMATE OF THE SOCK?

Sumner's hypothesis is that the marginal social return on investment, not the average social return, is the correct parameter to use in estimating the SOCK. As it is generally believed that the marginal social rate of return is less than the average return from private investment, he concludes that Jenkins' use of average rates of return on the net replacement cost of capital necessarily produces an upward bias to the estimated SOCK. 
This argument demonstrates a serious misunderstanding of the nature of the estimated rates of return from private investment employed in Jenkins' estimates. While it may be true that the investments which are postponed are those with lower expected returns, the value of this parameter is not measured by the return on the set of least profitable projects observed. The actual returns from investments will be distributed around their expected yields and thus the expected marginal return will be higher than the lowest observed returns. To measure the marginal expected return from postponed investments, therefore, it is essential to construct some form of weighted average of the observed returns.

The rates of return which were estimated express the current year's net value added of capital (both private and social) as a percentage of the net replacement value of all assets used in the operation of the sector. To interpret this as an unbiased estimate of the return from future investment it would be necessary to assume that any additional investment expenditures would augment the entire stock of assets across sectors according to the relative sizes of their existing stocks of assets.

However, this is not apt to occur. If private rates of return are low in a sector, it does not mean that the private investors are willing to invest in these low return assets. Rational investors, of course, will try to stay away from investing in low rate of return sectors in favor of those which have been earning higher than average rates of return. Hence, Jenkins' previous estimates give relatively too great a weight to the low return sectors such as aircraft and parts, railways, water transport and grain elevators into which few rational investors would be willing to make investments without considerable government participation and subsidization. It is not that no new investments will be made in these sectors, but that these sectors do not rely on the capital market for their investment funds. Governments are major participants in these sectors and, therefore, there is likely to be little postponement of investment in these areas when governments borrow. Hence, the assumption made by Jenkins that new investment will be distributed according to the relative size of the existing capital stock across sectors will serve to produce a downward bias in the estimated SOCK.

Even if the correct estimate of the expected marginal return on forgone investment is a weighted average of actual observed returns, the question of whether or not there will be a significant difference between the marginal expected rate of return from new investments and their average expected return is still an open one. If it were true that the marginal investments displaced or postponed by the expansion of the government sector would have had a significantly lower rate of return than the average return on new investments actually put in place, then we should observe private rates of return rising in the period between 1952 and 1974 as the public sector has expanded relative to the private sector. No such trend is observable for either the private or social rates of return. ${ }^{1}$

In deciding to undertake a new investment a firm will typically try to decide when is the most advantageous time to start the project. At the same time the firm usually cannot take the chance to hold back from making a new investment to allow demand pressures for the product of this investment to have a yield significantly larger than other potential investments. If the firm hesitates too long, then it is likely that other competitors will recognize the investment opportunity and step in to make the investment. Therefore, there will be a tendency for marginal expected rates of return on new investment and the average expected rates of return to converge.

In summary, there is scant evidence to suggest that the marginal expected return on new investment is significantly different from the average observed rates of return. However,

1 Data for 1952 to 1965 are presented in Jenkins (1972) and for the period 1965 to 1974 see Jenkins (1977a). 
because Jenkins weighted the rates of return across sectors by the net replacement value of the existing stock, he is likely to have introduced a downward bias in his estimate of the SOCK.

\section{IS MONOPOLY A CHARACTERISTIC OF HIGH RETURN SECTORS IN CANADA?}

Sumner's argument that the high rate of return sectors in Canada are characterized by monopolistic barriers to entry is almost totally void of factual content. Contrary to his statement, this issue has been studied in considerable detail in previous research on the analysis of rates of return from capital in Canada, Jenkins (1977a:92).

The sectors which have had relatively high private rates of return over the decade 1965 to 1974 are tobacco products, soft drinks, alcoholic beverages, highway and bridge construction, printing and publishing, machinery, motor vehicles, services and retail trade. Of these industries, only tobacco products and motor vehicles are characterized by a fairly high degree of concentration. Given the level of international trade in automobiles, it does not appear that this sector can be classified as being monopolistic. This leaves us with tobacco products which may not be as competitive as the other sectors. However, because of its small size it has a weight of less than $1 / 3$ of one per cent of the total in the estimation of the overall rate of return from investment in the industrial sector. It is unlikely that the degree of monopolistic barriers in Canadian industry is such as to either significantly restrain the expansion of investment in sectors or to alter the estimated value of the SOCK.

\section{ARE HISTORICAL RATES OF TAXATION OF CAPITAL HIGHER THAN CURRENT RATES OF TAXATION?}

Sumner has suggested that the investment tax credit and the manufacturing and processing incentives introduced in 1972 mean that the tax levied on a marginal investment in equipment by the manufacturing industry is currently not distinguishable from zero. While this is a theoretical possibility in a zero inflation environment, the interaction of the Canadian corporation income tax system with the increasing rate of inflation since 1972 has rendered this statement factually incorrect. Corporation income tax rates have risen continuously since 1970 when expressed as a percentage of the income generated by capital, Jenkins (1977b:49$51 \& 1977 \mathrm{a}: 245)$. Substantial theoretical and empirical literature exists which indicates that real corporation income tax rates will increase as a result of an inflationary situation such as has been the recent experience of Canada (Brunner, 1973 and Feldstein and Summers, 1979). Despite the good intentions of the designers of the 1972 tax incentive package for manufacturing, it would appear that an inflation rate of 5-8 per cent is more than enough to completely offset the tax reduction effect of these provisions. For the majority of businesses which are not eligible for these incentives the interaction of inflation with the corporation income tax has forced them to pay higher tax rates without any offsetting relief. In contrast to Sumner's prediction of a falling social rate of return from private investment due to expanded investment andlowertaxes, it would appear that the opposite situation is the more likely outcome.

\section{$\checkmark$ ARE SALES TAXES ON ALCOHOLIC BEVERAGES AND TOBACCO LEVIED TO COMPENSATE FOR THE SOCIAL EXTERNAL COSTS ARISING FROM THEIR CONSUMPTION?}

The point made by Sumner that the sales tax on these two items serves to compensate society 
for some of the negative externalities inflicted on it by consumers of these items is no doubt partially correct. On the other hand, if we consider that the people who pay the tax and consume these items bear the vast proportion of the social costs of these products, one is left wondering if governments have not been taxing these goods heavily because their price elasticity of demand is small and at the same time they are viewed politically as luxury consumption. To date I am not aware of any study which tries to compare the social ills generated by these two commodities with the tax revenues paid by those who consume them. However, in a study by McClure and Thirsk (1978) it has been shown that the income distribution impact of these consumptive taxes is very regressive and thus social welfare might be further reduced by their undesirable effect on the distribution of income.

As a whole, Sumner's arguments that the social opportunity cost of capital in Canada is less than the Jenkins estimate of 10 per cent are not a sound basis for making such a revision. There are, however, theoretical and empirical issues dealing with the adjustment of domestic consumption and foreign capital flows to government borrowing which could have an impact on the estimated SOCK. In a recent paper Burgess (1980) has explored some of these issues.

\section{R E F E R E N C ES}

Arrow, Kenneth J. and R.C. Lind (1970) 'Uncertainty and the Evaluation of Public Investment Decisions,' American Economic Review, 60:364-378.

Brunner, Roger (1973) 'Inflation, Deferral and the Neutral Taxation of Capital Gains,' $N a$ tional Tax Journal, 46:565-573.

Burgess, David (1980) 'The Social Discount Rate for Canada: Theory and Measurement,' mimeo (Ottawa: Energy, Mines and Resources Canada)

Campbell, Harry F. (1975) 'A Benefit/Cost Rule for Evaluating Public Projects in Canada,' Canadian Public Policy - Analyse de Politiques, I:2:171-175.

Dreze, Jacques H. (1974) 'Discount Rates and Public Investment: A Post-Scriptum,' Economics, $41: 161: 52-61$.

Feldstein, Martin and Laurence Summers (1979) 'Inflation and the Taxation of Capital Income in the Corporate Sector,' National Tax Journal, 32:445-470.

Harberger, Arnold C. (1969) 'On Measuring the Social Opportunity Cost of Public Funds,' in The Discount Rate in Public Investment Evaluation, Conference Proceedings of the Committee on the Economics of Water Resource Development, Western Agricultural Economics Research Council, Report No.17, Denver, 1-24.

Hirshleifer, Jack, James C. DeHaven and Jerome W. Milliman (1960) Water Supply: Economics, Technology and Policy (Chicago: University of Chicago Press)

Jenkins, Glenn P. (1972) 'Analysis of Rates of Return from Capital in Canada,' unpublished Ph.D. dissertation, University of Chicago.

- (1973) 'The Measurement of Rates of Return and Taxation from Private Capital in Canada,' in W.A. Niskanen et al. (eds.) Benefit-Cost and Policy Analysis in 1972 (Chicago: Aldine)

(1977a) Capital in Canada: Its Social and Private Performance 1965-1974, Discussion Paper No.98 (Ottawa: Economic Council of Canada)

- (1977b) Inflation: Its Financial Impact on Business in Canada (Ottawa: Economic Council of Canada)

Marglin, Stephen A. (1963) 'The Social Rate of Discount and the Optimal Rate of Investment,' Quarterly Journal of Economics, 77:95-111. 
McClure, C.E. amd W.R. Thirsk (1978) 'The Inequity of Taxing Iniquity: A Plea for Reduced Sumptuary Taxes in LDCs,' Economc Development and Cultural Change, 26:487503.

National Energy Board (1979) 'Submission by Government of Manitoba,' Omnibus Gas Hearings, Phase I, Calgary.

Sandmo, Agnar and Jacques H. Dreze (1971) 'Discount Rates for Public Investment in Closed and Open Economies,' Economics, 38:395-412.

Sjaastad, Larry A. and Daniel L. Wisecarver (1977) 'The Social Cost of Public Finance,' Journal of Political Economy, 85:513-547.

Sumner, M.T. (1980) 'Benefit-Cost Analysis in Canadian Practice,' Canadian Public Policy Analyse de Politiques, VI:2:389-393.

Treasury Board (1976) Benefit-Cost Analysis Guide (Ottawa: Ministry of Supply and Services) 